\title{
Influence of Polypropylene Fibre (PF) Reinforcement on Mechanical Properties of Clay Soil
}

\author{
Mazahir M. M. Taha $\mathbb{D}^{1,2}$ Cheng Pei Feng $\mathbb{D}^{1},{ }^{1}$ and Sara H. S. Ahmed ${ }^{3}$ \\ ${ }^{1}$ Civil Engineering Department, Northeast Forestry University, P.O. Box 150040, Harbin, China \\ ${ }^{2}$ Civil Engineering Department, Faculty of Engineering, Alzaiem Alazhari University, P.O. Box 1432 Khartoum North 13311, Sudan \\ ${ }^{3}$ Civil Engineering and Architecture Department, Zhejiang University 866 Yuhangtang Road, Xihu District, Hangzhou 310058, China
}

Correspondence should be addressed to Cheng Pei Feng; chengpeifeng@126.com

Received 31 October 2019; Revised 23 December 2019; Accepted 27 February 2020; Published 19 May 2020

Guest Editor: Jinjun Xu

Copyright (c) 2020 Mazahir M. M. Taha et al. This is an open access article distributed under the Creative Commons Attribution License, which permits unrestricted use, distribution, and reproduction in any medium, provided the original work is properly cited.

\begin{abstract}
This study investigated the effects of polypropylene fibre (PF) reinforcement on the mechanical behaviour of clay soil. Using clay soil and polypropylene fibres from China's Inner Mongolia and Hebei Provinces, respectively, a series of soil samples with $0 \%, 1.5 \%$, $2.25 \%$, and $3 \% \mathrm{PF}$ content by soil weight were subjected to compaction, shear strength, consolidation, California bearing ratio, and microstructure analyses. The study results indicate improved compaction, shear strength, consolidation, and the bearing ratio of the PF-stabilised clay soil. As the PF content increased, its maximum dry density increased and its optimum moisture content decreased; its angle of internal friction increased and its cohesion coefficient decreased; and its void ratio, consolidation coefficient, and hydraulic conductivity all decreased. Comparing the unstabilised ( $0 \%$ PF) and stabilised (3\% PF) clay soil, the void ratio, consolidation coefficient, and hydraulic conductivity decreased from 0.96 to 0.93 , from 2.52 to $2.34 \mathrm{~cm}^{2} / \mathrm{s}$, and from 1.12 to $1.02 \mathrm{~cm} / \mathrm{s}$, respectively. The optimum PF content was determined to be $3 \%$ by the weight of the soil, as this quantity resulted in the best improvement in soil properties.
\end{abstract}

\section{Introduction}

Highways, bridges, buildings, and hydraulic structures are at high risk for damage if constructed on a swelling soil such as clay. To improve the strength and compactability of clay soil in foundation applications, different stabilisation techniques have been established by targeting various soil parameters, including the shear strength, liquid limit, plasticity index, compaction, and consolidation coefficient. Common stabilisation techniques include the use of chemical additives [1-13], thermal energy [14-18], compaction, and reinforcement with plant-based or synthetic fibres [19-33]. Plantbased fibre reinforcement materials include straw, coir, palm, sisal, and jute and are available at a low cost. The use of synthetic fibre reinforcement materials such as polypropylene, nylon, rubber, or plastic also offers potential wastereduction benefits. As excessive waste materials pose public safety and logistical challenges regarding disposal [34-36], research into the use of waste materials to stabilise soil is presently a global trend.

Several previous studies have considered the effects of different fibre types on the mechanical properties of soil. Moghal et al. [37] evaluated the effectiveness of Fibre Cast (FC) and Fibre Mesh (FM) in different lengths and dosages on the unconfined compressive strength (UCS) of soil specimens. They observed that the fibre type, length, and dosage all affected the UCS of soil stabilised with lime. Puppala and Musenda [38] investigated the effects of fibre reinforcement on strength and volume changes in expansive soils. Their results show that the fibre reinforcement increased the UCS of the soil and reduced both its volumetric shrinkage and swelling pressures. Yadav and Tiwari [39] found that the use of rubber fibres decreased the compressive and tensile strengths of cement-stabilised clay soil but significantly increased the postpeak strength loss rate and altered the failure mechanism of the cement stabiliser. As the rubber fibre 
content increased, the soaked and unsoaked California bearing ratio (CBR) values decreased and increased, respectively. Moghal et al. [40] studied the effect of FC and FM on the CBR of specimens and found that the improvement in CBR increased with the quantity of fibre and fibre lengths. The maximum CBR occurred for a fibre content of $0.6 \%$ and fibre length of $12 \mathrm{~mm}$. Phanikumar and Singla [23] investigated the effects of nylon fibres on the swell-consolidation characteristics of a clay soil. They found that the use of nylon fibres improved the soil's secondary consolidation characteristics and that the swell potential and vertical swelling pressure decreased as the length of the fibres increased. Al-Akhras et al. [41] investigated the effect of nylon and palmyra fibre contents of $1 \%, 2 \%, 3 \%, 4$, and $5 \%$ by soil weight on the swelling properties of clayey soils. The results showed that, for the same quantity of fibre, the palmyra fibres had a greater effect than the nylon fibres in reducing the swelling pressure of the expansive soils. Moghal et al. [42] studied the effects of FC and FM in three dosages each $(0.2,0.4$, and $0.6 \%$ by soil weight), two fibre lengths each (6 and $12 \mathrm{~mm}$ ), and with and without lime treatments on the swell-consolidation. The results indicated that FC without lime reduced swelling, while the linear shrinkage decreased with the addition of fibres and lime treatment. Khan and Azam [43] studied the consolidation behaviour of clay slurry, they found that the void ratio significantly decreased following the virgin compression of clay slurry; the soil hydraulic conductivity also decreased because of the low porosity and high torsion. The consolidation and volume change coefficients decreased as the void ratio and hydraulic conductivity decreased but increased as the effective pressure decreased. Most recently, Cui et al. [44] found that the use of carbon fibre and nanosilica significantly improved the soil shear strength based on the internal friction angle and cohesion between the carbon fibres and soil.

To date, few studies have focused specifically on the consolidation coefficient and CBR of polypropylene fibre (PF) stabilised soil. Accordingly, this study investigated the effects of PF stabilisation on the mechanical properties of a clay soil. Using clay soil from China's Inner Mongolia and PF from Hebei Province, a series of laboratory tests were performed to determine the compaction, shear strength, consolidation, and bearing ratio of soil with and without PF stabilisation. The stabilised test specimens were prepared using $0.75 \%$, $1.5 \%, 2.25 \%$, and $3 \%$ PF content by soil weight. The results of this study demonstrate the potential for the use of PF as part of a soil stabilising technique, advancing the state of knowledge regarding the practical stabilization of clay soils.

\section{Materials and Methods}

\subsection{Materials}

2.1.1. Clay Soil. The clay soil used in this study was collected in the La Bu Dalin subdistrict of Erguna in China's Inner Mongolia Province. Samples were obtained from $15 \mathrm{~cm}$ below ground, placed in a plastic bag to retain moisture, and transported to the Northeast Forestry University laboratory for preliminary analysis. Table 1 summarises the clay
TABLE 1: Index properties of soil.

\begin{tabular}{lc}
\hline Property & Value \\
\hline Specific gravity & 2.58 \\
Moisture content (\%) & 13.35 \\
Liquid limit (\%) & 67 \\
Plastic limit (\%) & 36.09 \\
Plasticity index (\%) & 30.91 \\
Compaction parameters & \\
Optimum moisture content (\%) & 27.38 \\
Maximum dry density $\left(\mathrm{g} / \mathrm{cm}^{3}\right)$ & 1.52 \\
Shear strength parameters & \\
$\mathrm{C}\left(\mathrm{kN} / \mathrm{cm}^{2}\right)$ & 175 \\
$\Phi\left({ }^{\circ}\right)$ & 2.83 \\
\hline
\end{tabular}

soil properties determined according to the American Society for Testing and Materials (ASTM) Standards [45-50]. The particle size distribution of the soil is displayed in Figure 1. The soil was classified as high-plasticity clay $(\mathrm{CH})$ according to the distribution of particle sizes and based on Indian Standard IS: 1498-1970.

2.1.2. Polypropylene Fibre. Fibres are one of the most widely used synthetic materials for reinforcing soil because of their nontoxicity, corrosion resistance, and high tensile strength. The PF used in this study was produced in China's Hebei Province. The PF was $12 \mathrm{~mm}$ in length $[51,52]$ with a mean diameter of $0.034 \mathrm{~mm}$. Table 2 summarises the additional properties of the PF.

2.2. Test Specimen Preparation. To prepare the clay soil for testing, the sample was first dried in an oven at $50^{\circ} \mathrm{C}$ for $24 \mathrm{~h}$ then mixed manually with $0 \%, 0.75 \%, 1.5 \%, 2.25 \%$, and $3 \%$ PF by dry weight of soil and distilled water for at least $10 \mathrm{~min}$ to create a series of test mixtures. These mixtures were then placed in plastic bags, where they were continuously shaken for at least $5 \mathrm{~min}$ to remove all air. Finally, after squeezing any remaining air out of each bag by hand, the plastic bags were sealed and stored in desiccators for $24 \mathrm{~h}$.

Immediately prior to testing, the materials were remixed in the plastic bags by shaking and squeezing the bags. The resultant mixtures contained no clumps larger than $5 \mathrm{~mm}$ in diameter. Sufficient numbers of unstabilised ( $0 \%$ PF) and stabilised $(0.75 \%, 1.5 \%, 2.25 \%$, and $3 \%$ PF by dry weight of the soil) test specimens were prepared from these mixtures to allow for a minimum of three measurements per test; these measurements were then averaged to produce the final test results.

\subsection{Experimental Methods}

2.3.1. Photoelectric Liquid-Plastic Limits Test. The liquidplastic limit test was conducted using the GYS-2 photoelectric liquid-plastic tester from the Nanjing Ningxi Soil Instrument Co., Ltd, in Nanjing, China. The liquid-plastic limits were measured by the cone depth of the soil with the cone mass of $100 \mathrm{~g}$ and cone angle of $30^{\circ}$. A cone penetrator was used to determine the liquid limit (WL), plastic limit (WP), 


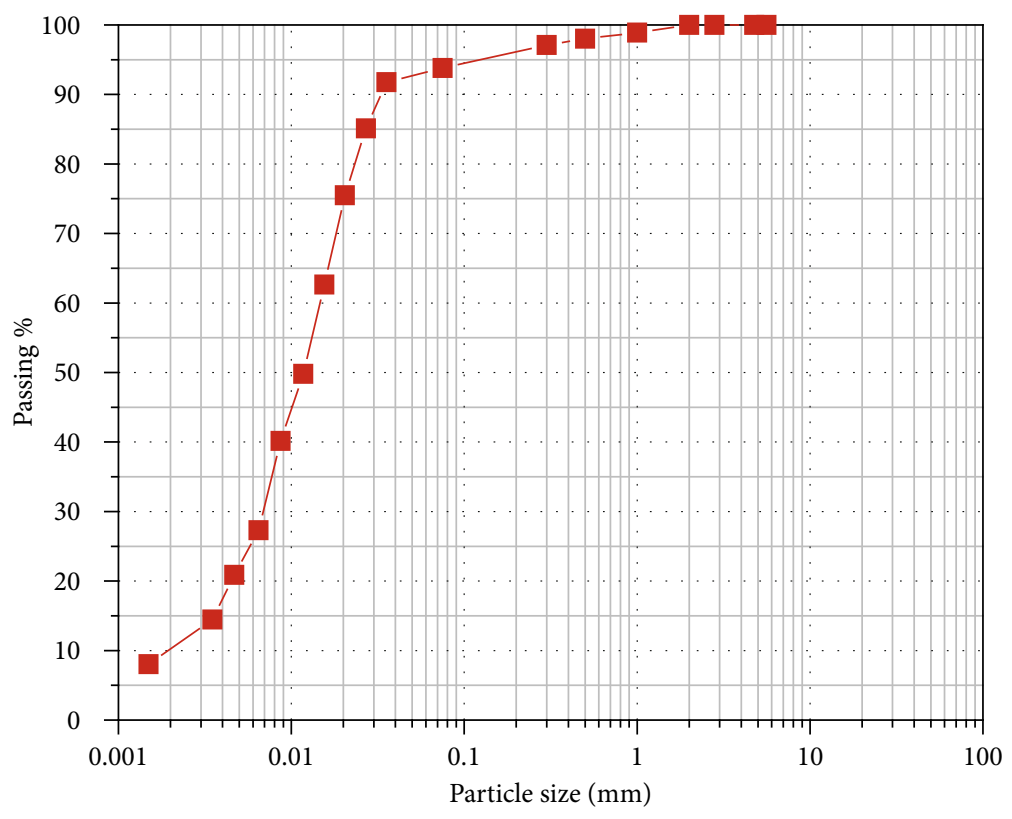

Natural soil

Figure 1: Particle size distribution of the natural soil.

TABle 2: Properties of polypropylene fibre.

\begin{tabular}{lc}
\hline Property & Value \\
\hline Density & $0.91 \mathrm{~g} / \mathrm{cm}^{3}$ \\
Cut length & $12 \mathrm{~mm}$ \\
Diameter & $0.034 \mathrm{~mm}$ \\
Colour & White \\
Humidity & $<0.1 \%$ \\
Acid resistance & Very good \\
Alkali resistance & Very good \\
\hline
\end{tabular}

and plasticity index $(P I)$ of the soil with and without PF. Figure 2 presents a schematic diagram of photoelectric liquid-plastic limit testing apparatus used in this study. The principle of the photoelectric test is based on the GB/T 50123-1999 standard soil test method and JTG E40-2007 method of soil testing for highway engineering methods [53, 54]. The moisture content $(w c)$ was measured corresponding to each penetration depth of the cone ( $\leq 5 \mathrm{~mm}, 9-11 \mathrm{~mm}$, and $20 \pm 0.2 \mathrm{~mm}$ ) to draw Lines $A B$, $\mathrm{AC}$, and $\mathrm{AD}$. The $W L$ was determined from the test result as the moisture content at which the $h p$ equal to $20 \pm$ $0.2 \mathrm{~mm}$ using this $W L$ in Eq. (1) to determine the penetration depth $h p$. The $P L$ was then determined from Figure 3, based on the penetration depth obtained from Eq. (1) for each of the three straight lines $A B, A C$, and $\mathrm{AD}$ of the soil specimen. Consequently, the $P I$ was calculated by using Eq. (2).

$$
h p=W_{L} /\left(0.524 W_{L}-7.606\right)
$$

where $h p$ is the cone penetration depth and $W L$ is the liquid limit.

$$
P_{I}=W_{L}-P_{L}
$$

where $P I$ is the plasticity index, $W L$ is the liquid limit and $P L$ is the plastic limit.

2.3.2. Proctor Compaction Test. Proctor compaction tests were conducted on the unstabilised and stabilised test specimens according to ASTM Standard D698-00a (2006) [49] to determine their maximum dry density $\left(\mathrm{MDD}, \mathrm{g} / \mathrm{cm}^{3}\right)$ and optimum moisture content (OMC, \%) as indicators of their compaction potential. The compaction properties of the unstabilised soil and the stabilised soils with varying PF contents were subsequently compared.

2.3.3. Triaxial Compression Test. Triaxial compression tests were performed to measure the shear strength of the clay soil specimens based on their angle of internal friction $\left(\Phi,{ }^{\circ}\right)$ and cohesion coefficient $\left(c, \mathrm{~kg} / \mathrm{cm}^{2}\right)$. Unstabilised and stabilised specimens in their MDD and OMC states were placed in moulds measuring $80 \mathrm{~mm}$ in length with a diameter of $39.1 \mathrm{~mm}$. Triaxial compression tests were subsequently performed using the fully automatic TSZ-1 triaxial test apparatus (Nanjing Ningxi Soil Instrument Co., Ltd., Nanjing, China). During testing, the rate of axial strain was set at $0.800 \mathrm{~mm} / \mathrm{min}$, the axial force at $10 \mathrm{kN}$, and the confining pressures at 100,200 , and $300 \mathrm{kPa}$.

2.3.4. Consolidation Test. Consolidation tests were performed to measure the consolidation of the clay soil specimens based on the void ratio $(e)$, consolidation coefficient $\left(c v, \mathrm{~cm}^{2} / \mathrm{s}\right)$, and hydraulic conductivity $(k, \mathrm{~cm} / \mathrm{s})$. The unstabilised and stabilised specimens, again in their MDD and OMC states, were placed in ring moulds measuring $20 \mathrm{~mm}$ thick with a diameter of $61.8 \mathrm{~mm}$. The consolidation tests were 


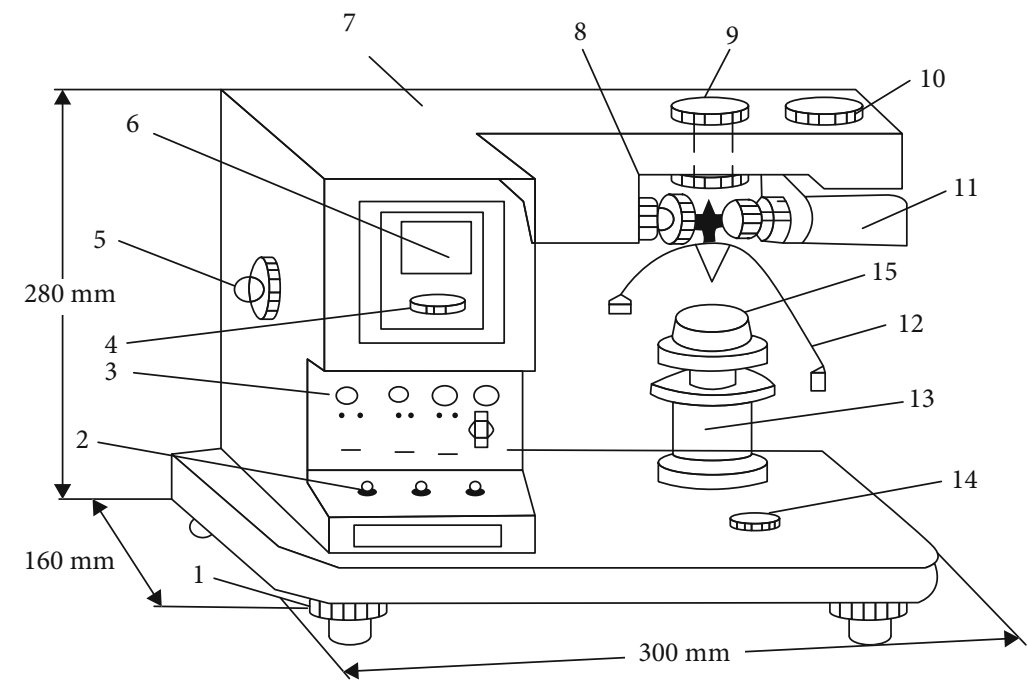

FIGURE 2: Schematic diagram of photoelectric liquid/plastic limit testing machine: (1) water adjusting screw; (2) control switch; (3) indicator light; (4) zero line adjusting screw; (5) reflector adjusting screw; (6) screen; (7) housing; (8) objective adjustment screw; (9) battery devices; (10) light source adjusting screw; (11) light source; (12) cone instrument; (13) lift table; (14) horizontal bubbles; (15) soil cup.

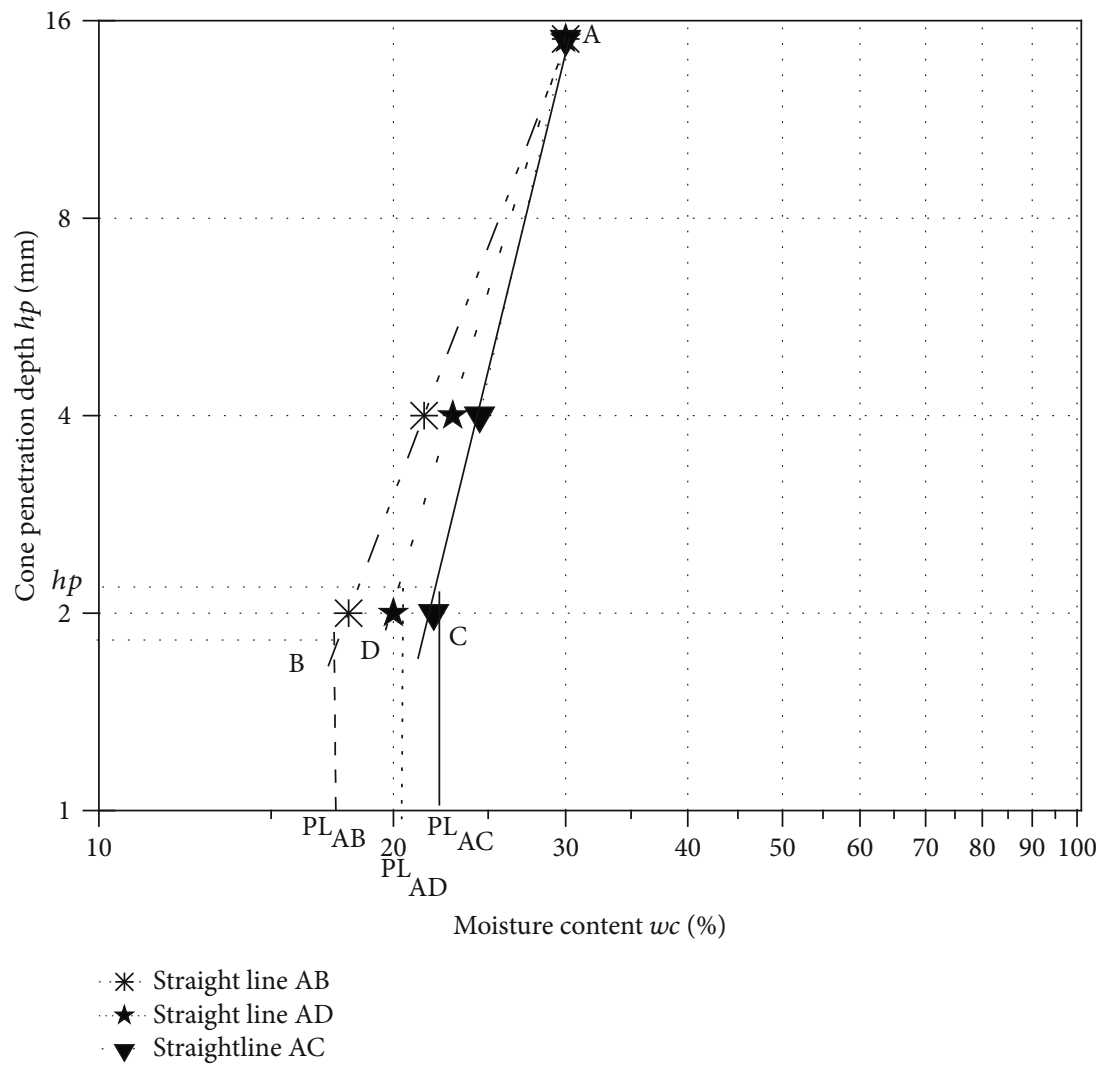

FIGURE 3: Relationship between the cone penetration depth $(h p)$ and moisture content $(w c)$.

subsequently performed using the fully automatic GZQ-1 pneumatic consolidometer testing machine with a capacity of $4.5 \mathrm{kN}$ (Nanjing Ningxi Soil Instrument Co., Ltd., Nanjing, China). Comprised of a pneumatic controller, multiple channels, a communication converter, and a data system, this device was used to determine the compression properties of the soil under different loads and pressures $(12.5,25,50$, $100,200,300,400$, and $800 \mathrm{kPa}$ ). The errors in test force and displacement were found to be within $\pm 1 \%$ of the indicated values. 


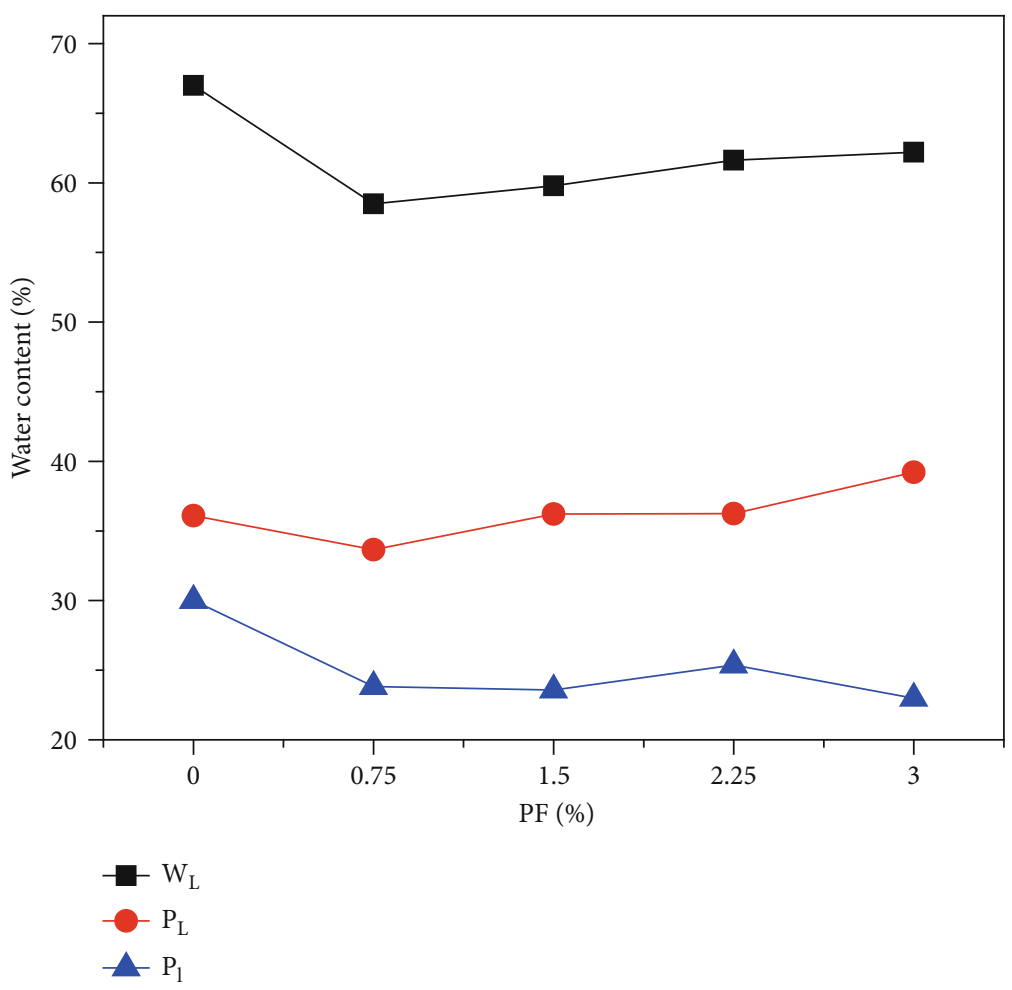

Figure 4: Effect of PF on the Atterberg limits of the soils.

2.3.5. California Bearing Ratio Test. To determine the CBR (\%) of the clay soil, we performed CBR tests in accordance with JTG-E40-2007 [54]. The soil mixture was filled in the cylindrical mould of $150 \mathrm{~mm}$ diameter and $180 \mathrm{~mm}$ height in three equal layers and each layer was compacted with 98 blows per layer with a loading rate of $1.25 \mathrm{~mm}$ per minute. The soil samples for unstabilised and stabilised soil were prepared as per prescribed standard procedures and guidelines. The CBR test was performed on the soaked samples, and the $\mathrm{CBR}$ is the ratio of force per unit area required to penetrate into a soil mass with a circular plunger of $50 \mathrm{~mm}$ diameter at the rate of $1.25 \mathrm{~mm} / \mathrm{min}$. The CBR tests on unstabilised and stabilised soil for soaked conditions were carried out as per the guidelines prescribed in JTG-E402007. The specimens for the tests were prepared at the MDD and OMC of the mixtures. For soaked conditions, the specimens were soaked in water for $96 \mathrm{~h}$ prior to testing [39]. The CBR value of unstabilised and stabilised soil was obtained by dividing the loads and the corresponding forces to achieve 2.5 and $5 \mathrm{~mm}$ penetration to the standard loads of 1370 and $2055 \mathrm{~kg}$, respectively. The associated CBR values (\%) were subsequently determined.

2.3.6. Microstructure Analysis. As a final task in this study, scanning electron microscopy (SEM) and energy dispersive $\mathrm{X}$-ray (EDX) analyses were performed to compare the microstructures of the unstabilised and stabilised test specimens. These methods are widely used to identify and characterise microstructures, particle sizes, and chemical compositions in a broad range of current research practices.

\section{Results and Discussion}

3.1. Photoelectric Liquid - Plastic Limit. As indicators of photoelectric liquid-plastic limit, Figure 4 shows the $W L, P L$, and $P I$ of the unstabilised and stabilised test specimens. As the PF content increased, its $W L$ and $P L$ decreased and then increased while the $P I$ decreased. The observed decrease in the $W L$ and $P L$ when PF is first introduced in the soil could be attributed to the effect of the resulting interlocking and friction between the PF and soil particles. The WL of the untreated soil was $67 \%$, which decreased $4.8 \%$ to $62.20 \%$ at $3 \%$ PF. Similarly, the PI of the unstabilised soil was $30.01 \%$, which then decreased $7.03 \%$ to $22.98 \%$. The observed increase in the WL of the stabilised soil can be attributed to the replacement of soil grains by PF. The PF-stabilised soil maintains more material continuity than the unstabilised soil, and the PF does not absorb moisture. The observed increase in $W L$ with PF content is likely also due to the fact that the type of mixture, the relative amount of clay mineral, and the consistency limits of the mixture changed. It is clear that an addition of PF was sufficient to enhance the workability of the soil by reducing the PI. Mishra and Gupta [55] also confirmed that the PI decreased when the (PET) fibre in combination with the fly ash increased.

3.2. Soil Compaction. To investigate the compaction potential of the soils, the MDD and OMC of the unstabilised and stabilised soils were determined with the results depicted in Figure 5. Increasing the PF content caused a corresponding increase in the MDD and decrease in the OMC. Comparing the unstabilised $(0 \% \mathrm{PF})$ and stabilised $(3 \% \mathrm{PF})$ clay soils, 


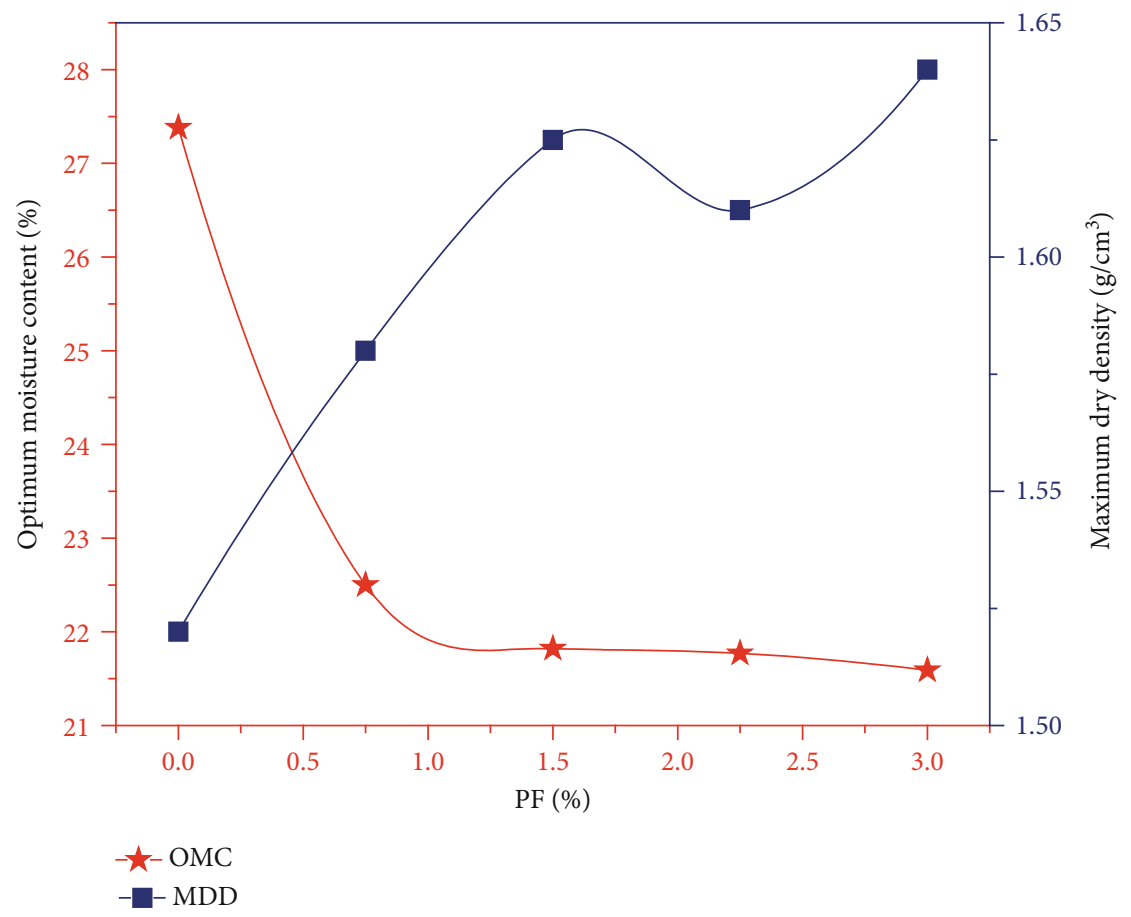

FIgURE 5: Maximum dry density (MDD) and optimum moisture content (OMC) for unstabilised and PF-stabilised soils.

the MDD increased $7.9 \%$ from $1.52 \mathrm{~g} / \mathrm{cm}^{3}$ to $1.64 \mathrm{~g} / \mathrm{cm}^{3}$, whereas the OMC decreased $5.8 \%$ from $27.4 \%$ to $21.6 \%$. As $\mathrm{PF}$ has a lower OMC than the clay soil particles, increasing the PF content reduces the overall OMC of the combined system. Notably, the observed increase in MDD may be due to a decrease in the interstitial voids in the PF-stabilised soil. The small decrease in MDD for a PF content of $2.25 \%$ may be due to the presence of overlapping PF in the matrix, which creates pockets of low density. This may also due to the replacement of a certain quantity of compacted soil by an equivalent volume of $\mathrm{PF}$, resulting in a loss of compaction efficiency due to the PF overlap. A previous report by Tran et al. [29] demonstrated that the length and content of soil matrix fibres have a significant effect on the MDD and OMC. Similar to the current study, an increase in fibre content was observed to lead to an increase in MDD and a decrease in OMC. These findings are consistent with results from previous studies by Yadav and Tiwari [39].

3.3. Triaxial Compressive Test. The triaxial compressive test results for the unstabilised and PF-stabilised soils were analysed to determine the angle of internal friction $(\Phi)$ and cohesion coefficient $(c)$ shear strength parameters, with the results shown in Figure 6. Clearly, the PF improved the angle of internal friction and cohesion of the stabilised soil. The optimal PF content was 3\%, at which these samples exhibited the maximum angle of internal friction and lowest cohesion coefficient. As the PF stabilisation enhanced the interlocking between soil particles, the angle of internal friction of PF stabilised soil increases. A reasonable explanation for the observed temporary decrease in the angle of internal friction is that the PF present in the matrix stuck together to the form lumps that created pockets of low density in the matrix, or because large pores otherwise formed in the fibre-soil matrix. These findings are consistent with previously reported results $[12,44,51,56]$.

3.4. Consolidation. An important concept was proposed by Zeng et al. [57], in which compressibility, shear resistance, and hydraulic conductivity are considered to be interdependent and representative of the same physical phenomenon. Accordingly, in this study, a consolidation test utilizing a modified oedometer provided data to analyses variations in compressibility and hydraulic conductivity while increasing the stress applied during compression. Previous studies on clay compressibility were used as guides to evaluate the clay void ratio. To study the consolidation potential, the void ratio (e) was obtained as a function of effective pressure $(P$, using a logarithmic scale) for the unstabilised and stabilised soils; the results are depicted in Figure 7. The stabilised soil specimens had consistently lower void ratios than the unstabilised soil specimen: the void ratio markedly decreased from 0.96 to $0.86(0 \% \mathrm{PF})$ and from 0.93 to $0.73(3 \% \mathrm{PF})$. This decrease can be attributed to low porosity and interlocking and friction between the PF and soil. Phanikumar and Singla [23], previously demonstrated that unreinforced expansive clay soils from Amalapuram, AP, India, attained the highest equilibrium void ratio and that the fibre-reinforced expansive clays attained lower equilibrium void ratios upon saturation by inundation. Fibre-reinforcement of the expansive clay specimens induces an interlocking effect and a friction effect, resulting in a further decrease in the equilibrium void ratio. The same phenomenon was reported by Zeng et al. [57] where the $e-\log P$ compression curves of undisturbed soils generally lie above the remoulded specimen curves. 


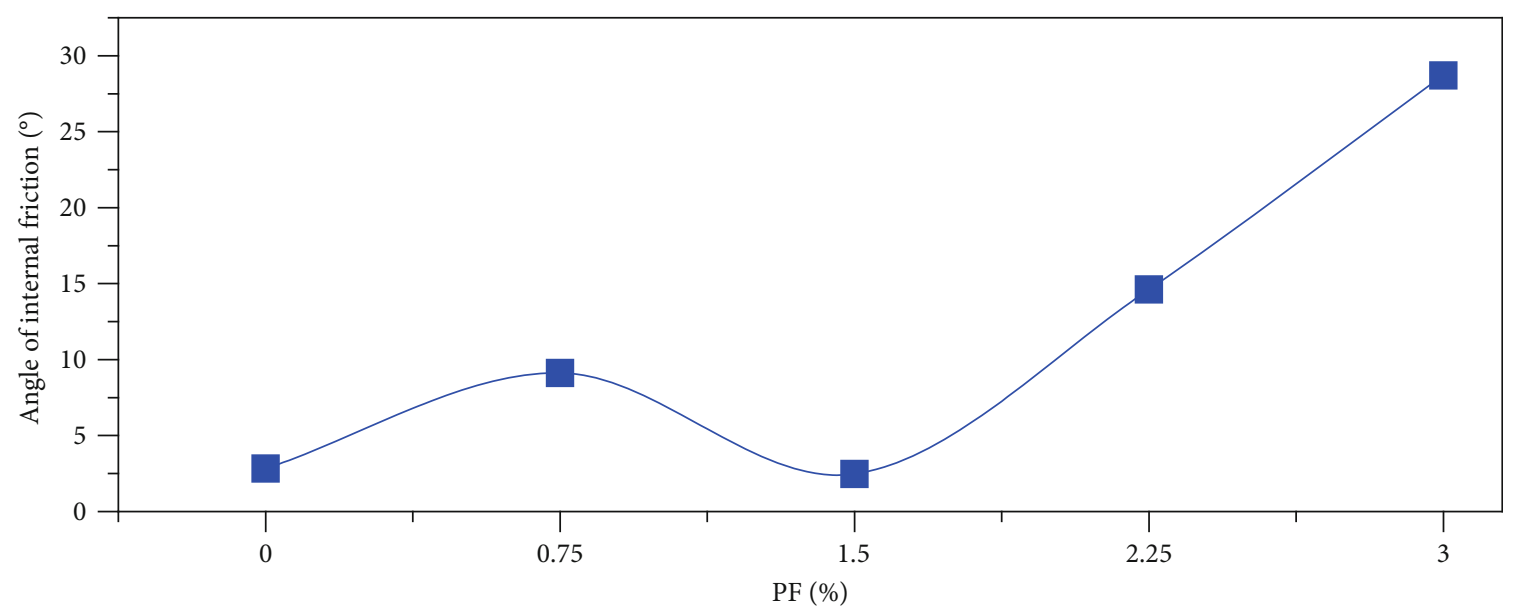

(a)

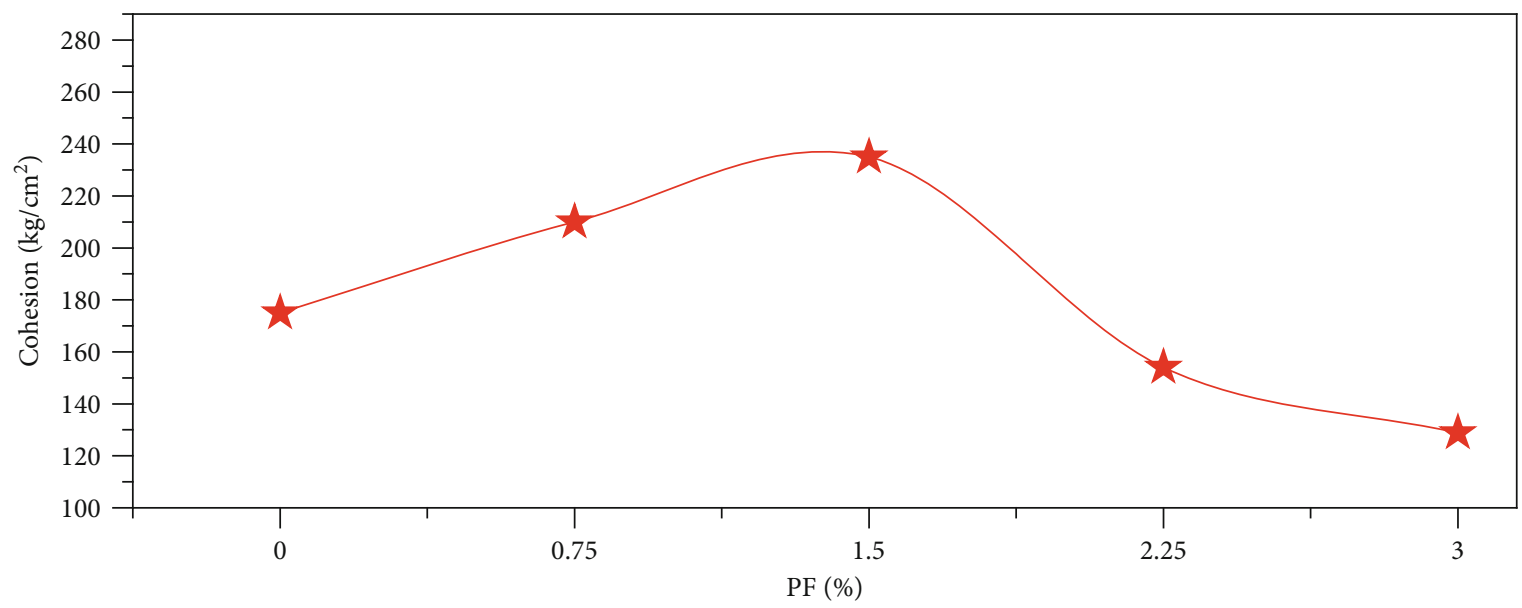

(b)

Figure 6: Relationship between PF content and shear strength parameters (a) angle of internal friction and (b) cohesion.

Based on the void ratio values in Figure 7, the rate of consolidation using the consolidation coefficient was determined. Figure 8 shows the consolidation coefficient $(\mathrm{Cv})$ as a function of effective pressure $(P$, using a logarithmic scale) for the unstabilised and stabilised soil specimens. As the PF content increased, the $C v$ decreased. Over the range of effective pressures studied, the $C v$ values ranged from 2.52 to $1.71 \mathrm{~cm}^{2} / \mathrm{s}$ for the unstabilised ( $0 \% \mathrm{PF}$ ) clay soil and from 2.34 to $1.40 \mathrm{~cm}^{2} / \mathrm{s}$ for the stabilised $(3 \%$ PF) clay soil. This decrease in $C v$ can be attributed to the initial clay soil conditions (e.g., water content or void ratio), the formation of a torsional flow path in the clay soil, or the clay soil inherent properties (e.g., specific gravity, grain size distribution, or mineral composition). Khan and Azam [43] also confirmed that the $C v$ behaviour of clay slurries decreased with an increase in effective pressure but increased with increasing $e$ values.

Similar to the $e-\log P$ compression curves, the $k-e$ curves of the clays, shown in Figure 9, indicate that the vertical hydraulic conductivity $(k)$ of the unstabilised soil specimens was higher than that of stabilised soil specimens for the same $(e)$ value. The hydraulic conductivity was measured throughout the test up to the applied pressure reached
$800 \mathrm{kPa}$. The hydraulic conductivity was observed to increase with the increasing void ratio and decrease with increasing PF content, in a manner consistent with the previously observed trends of the void ratio and consolidation coefficient. Within the range of void ratios studied, the hydraulic conductivity decreased from its maximum values for a $\mathrm{PF}$ content of $0 \%(1.12$ to $0.83 \mathrm{~cm} / \mathrm{s})$ to its minimum values for a PF content of $3 \%(1.02$ to $0.53 \mathrm{~cm} / \mathrm{s})$. As noted previously, this reduction in hydraulic conductivity can be attributed to the interlock between soil particles and the PF surface. These findings are consistent with results from some previous studies $[57,58]$. However, the FM fibre type and a fibre content of $0.6 \%$ were found to increase the hydraulic conductivity compared with the FC fibre type and $0.2 \%$ fibre content [59]. Divya et al. [60] studied the hydraulic conductivity of soil with different fibre types, dosages, and lengths, finding that shorter fibres and lower fibre contents decreased the hydraulic conductivity of the soil.

3.5. California Bearing Ratio. The CBR testing was performed on 4-day soaked samples and the results for the unstabilised and PF-stabilised soils are plotted in Figure 10. The results indicate that the addition of PF increases the 


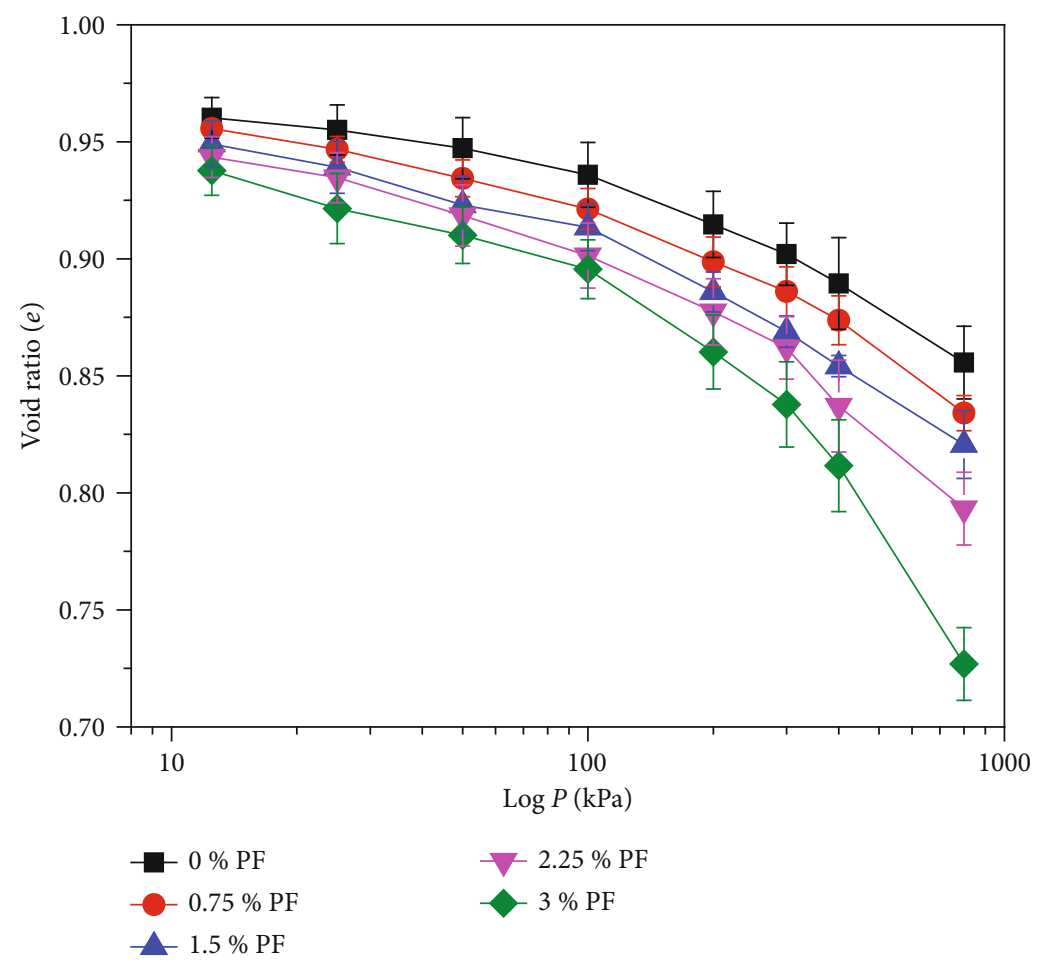

Figure 7: Void ratio $(e)$ and $\log P$ values for unstabilised and PF-stabilised soils.

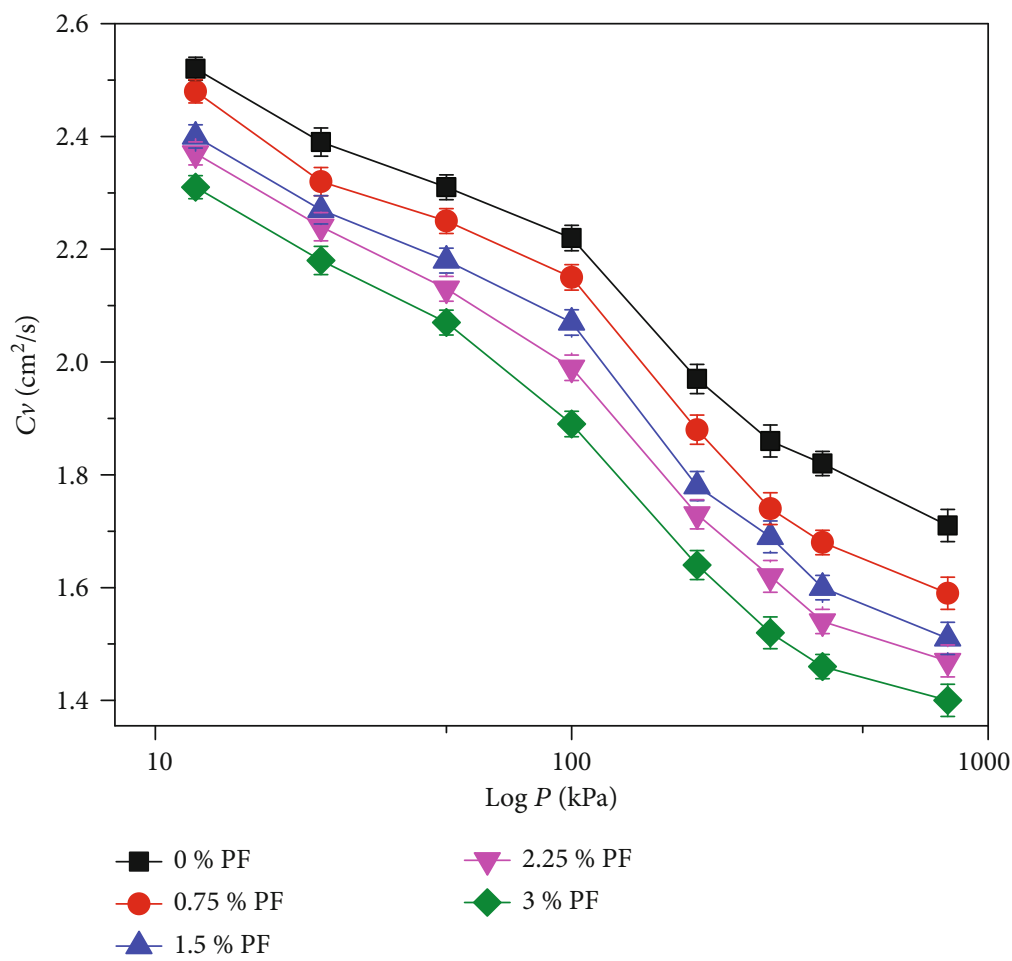

FIGURE 8: Coefficient of consolidation $(C v)$ for unstabilised and PF-stabilised soils.

CBR, which is indicative of an improvement in soil strength. The highest CBR was observed for PF contents of $3 \%$ by weight of soil. This is due to the fact that a higher $\mathrm{PF}$ content increases the interfaces between the fibres and the particles of the soil, so that greater friction is mobilised in the form of cohesion, assisted by the rough micro surface texture of the PF. This finding is similar to other recent results in which the addition of fibres was 


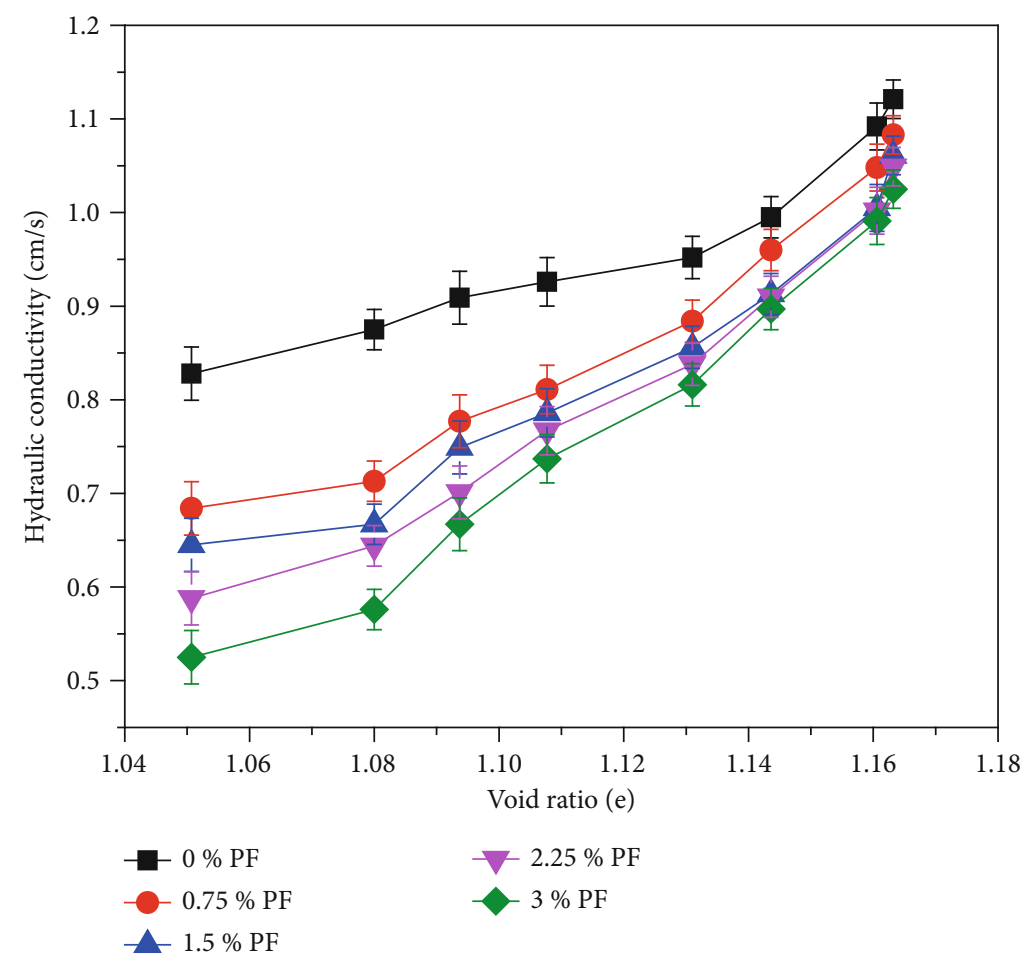

FIGURE 9: Hydraulic conductivity and void ratio relationship.

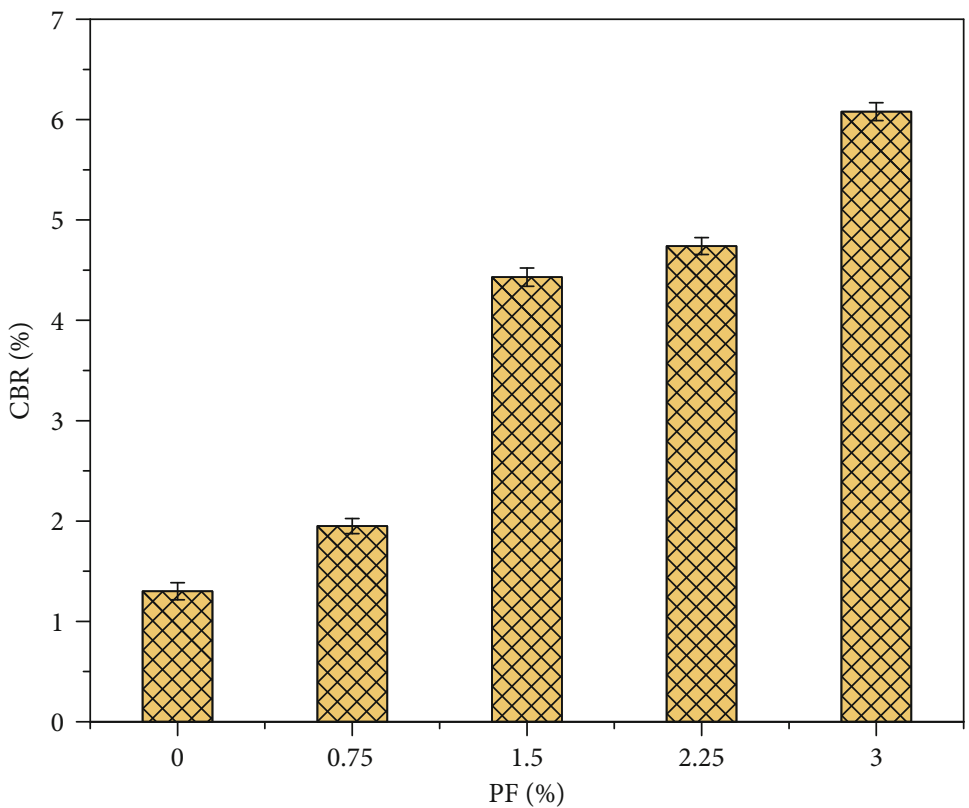

FIgURE 10: Effect of PF content on CBR value.

observed to increase the CBR in a variety of clays [9, 39, 40]. Moghal et al. [40] used two different types of synthetic fibres (FC and FM) in different quantities and lengths to determine the effects on the CBR. They determined that the CBR value increased with higher fibre contents and longer fibre lengths, and that this effect was most notable when lime was used as a stabiliser. Notably,
IRC: $37-2011$ states the thickness of pavements under a given traffic loading condition can be decreased as the CBR value increases. Consequently, the incorporation of fibre-reinforcement in soils could ultimately result in substantial cost savings when constructing roads on poor soils due to the potential reduction in the total required thickness of the road surface under selected traffic loads [55]. 


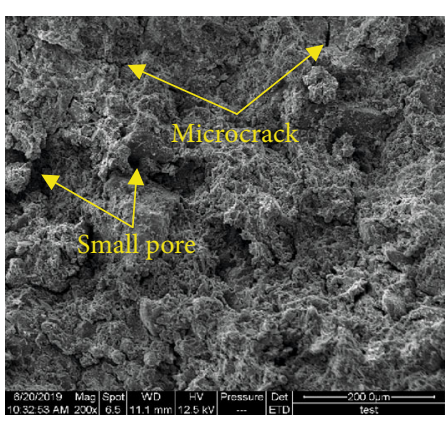

(a)

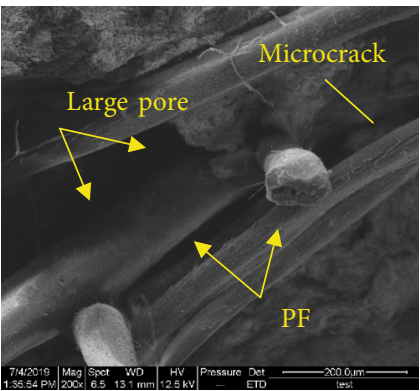

(c)

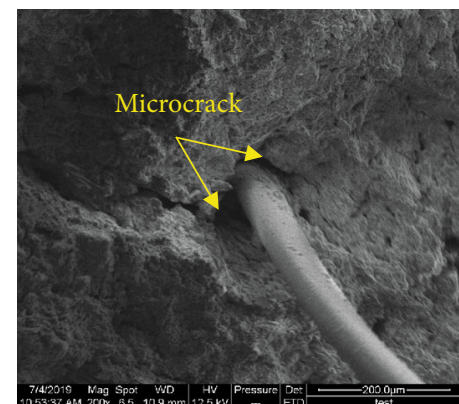

(b)

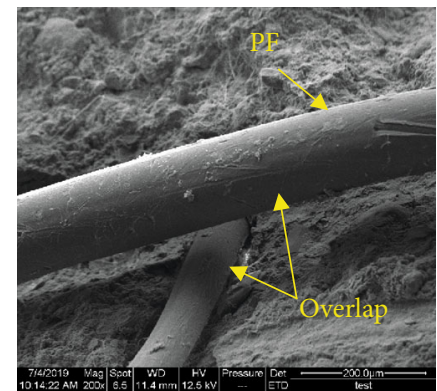

(d)

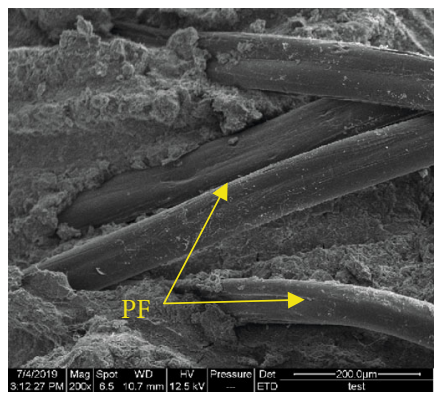

(e)

Figure 11: SEM images of (a) untreated soil, (b) soil with $0.75 \% \mathrm{PF}$, (c) soil with $1.5 \% \mathrm{PF}$, (d) soil with $2.25 \% \mathrm{PF}$, and (e) soil with $3 \%$ PF.

3.6. Microstructure Analysis. The microstructures of the unstabilised and stabilised test specimens were compared using the results of the SEM and EDX analyses shown in Figures 11 and 12, respectively. The SEM images show distinct microstructural differences between the unstabilised (Figure 11(a)) and stabilised (Figures 11(b)-11(e)) clay soils. The bond between the soil and PF, which is responsible for the observed improvements in the strength and stability of the soil, can be seen in the microstructural phase of the specimens with different PF contents in Figures 11(b), 11(d), and 11(e). Note that a gap can be observed at the interface between the soil and PF specimen in Figure 11(c): this large pore and other microcracks in the soil and on the PF surface may be responsible for the low matrix density reported in section 3.3. This supports the idea that the observed decrease in the angle of internal friction and cohesion was due to the weak interfacial interaction between PF and soil, causing the PF in the matrix to stick together and form lumps that caused pockets of low density in the matrix. Similarly, the effects of this weak interfacial interaction between the soil and $\mathrm{PF}$ and overlapping of PF can be seen in Figure 11(d), and may be responsible for the observations in section 3.2.

The EDX analysis results (Figure 12) show a few distinct differences between the chemical compositions of the unstabilised and stabilised clay soils. The PF itself contained varying amounts of $\mathrm{O}, \mathrm{C}, \mathrm{Na}, \mathrm{Mg}, \mathrm{Al}, \mathrm{Si}, \mathrm{K}, \mathrm{Ca}$, and $\mathrm{Fe}$. The $1.5 \%$ PF-stabilised test specimen in Figure 12(c) accordingly shows higher contents of $\mathrm{Ca}, \mathrm{Al}$, and $\mathrm{O}$ but a lower content of $\mathrm{C}$ than in the unstabilised specimens; this variation is likely due to replacement of soil particles by PF. The increase in Ca results in a more brittle soil system behaviour. This may be responsible for the observed low matrix density in section 3.3, as brittle soil would make the PF present in the matrix more likely to stick together and form lumps, causing pockets of low density.

\section{Conclusions}

In this study, the effects of PF content on the geotechnical properties of a clay soil were investigated using a series of 


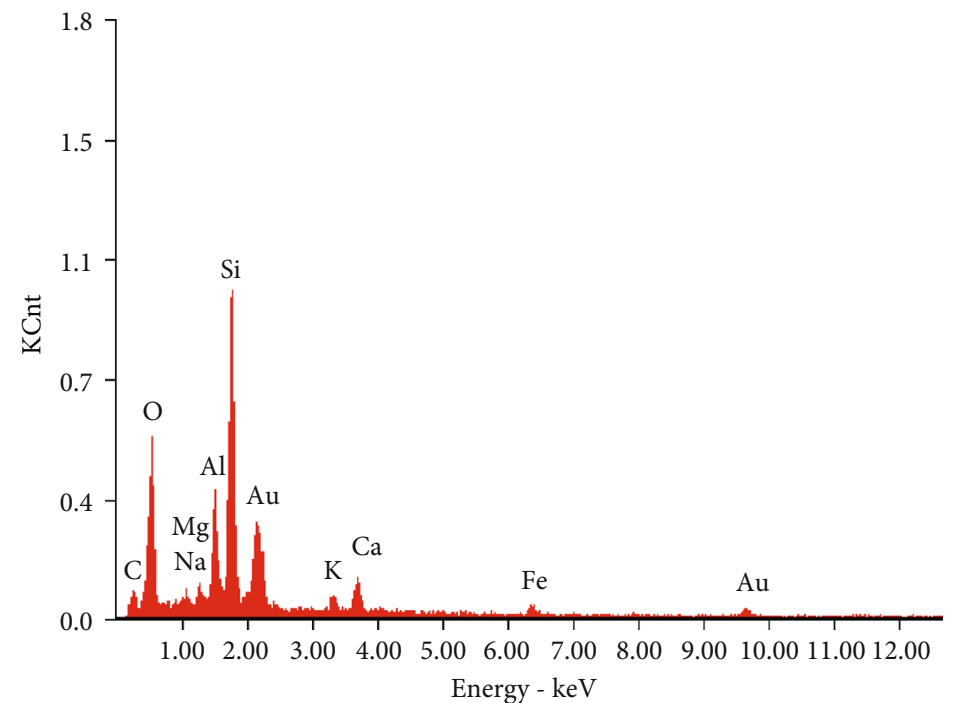

(a)

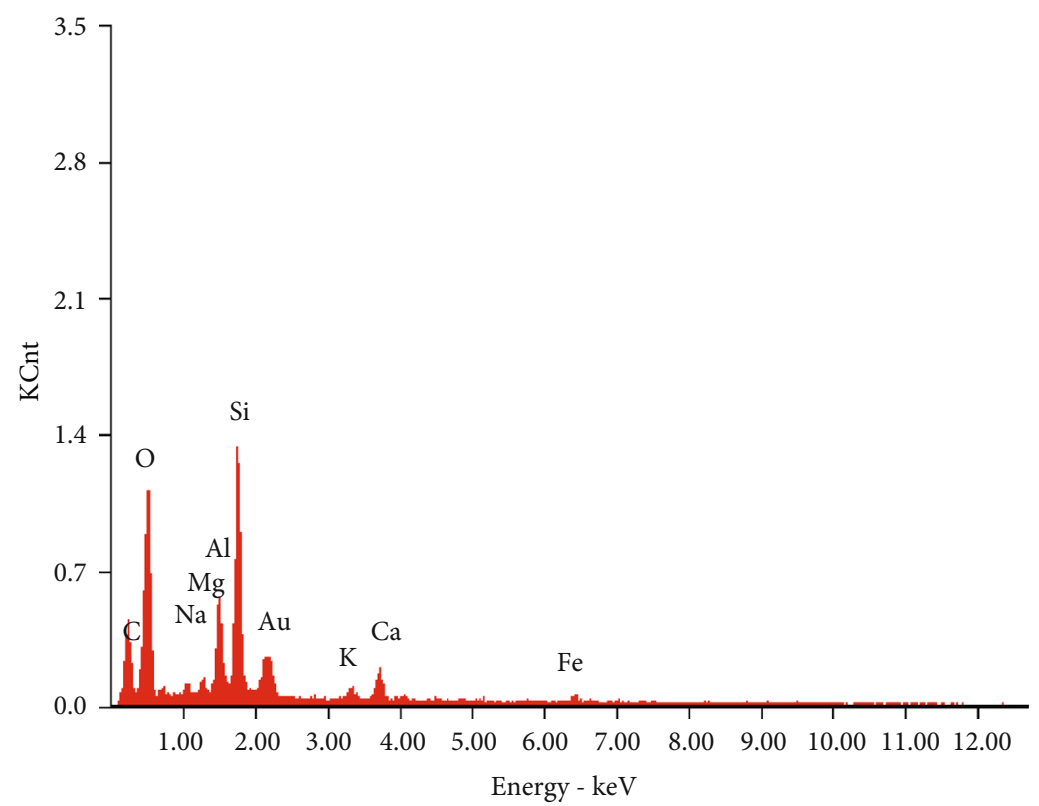

(b)

Figure 12: Continued. 


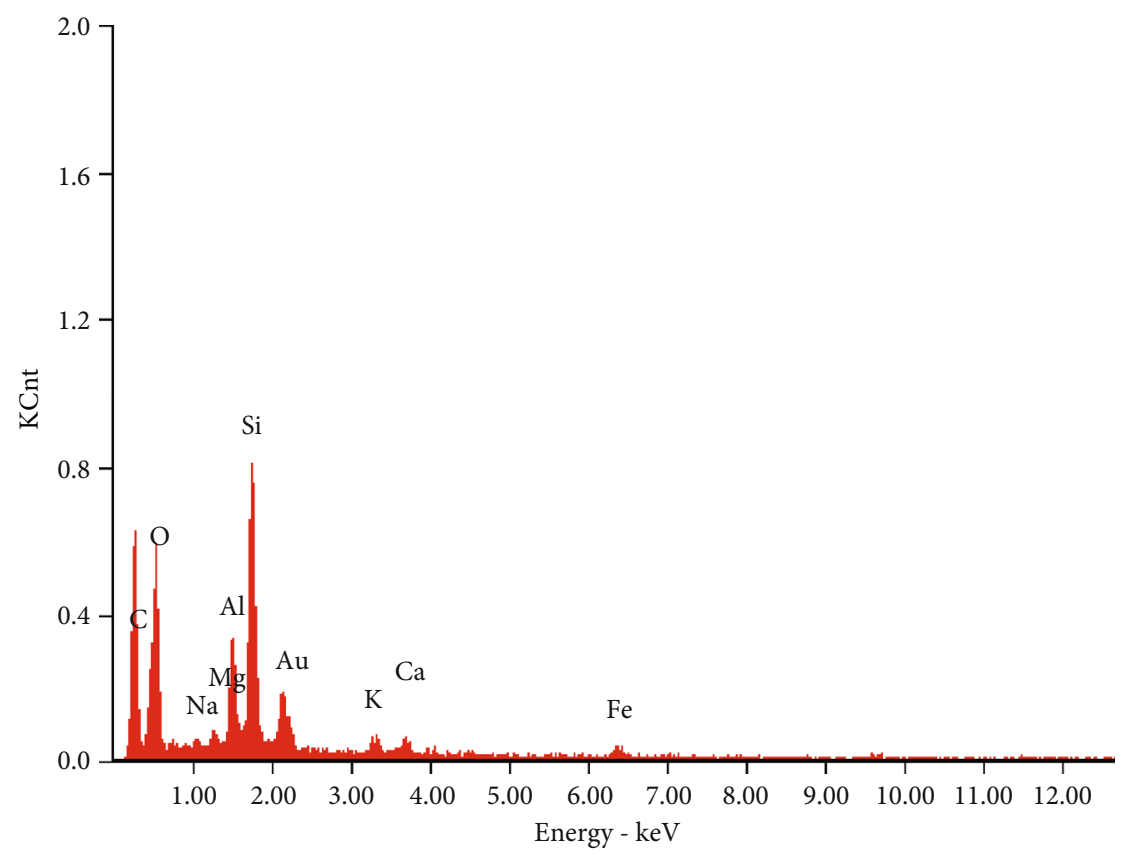

(c)

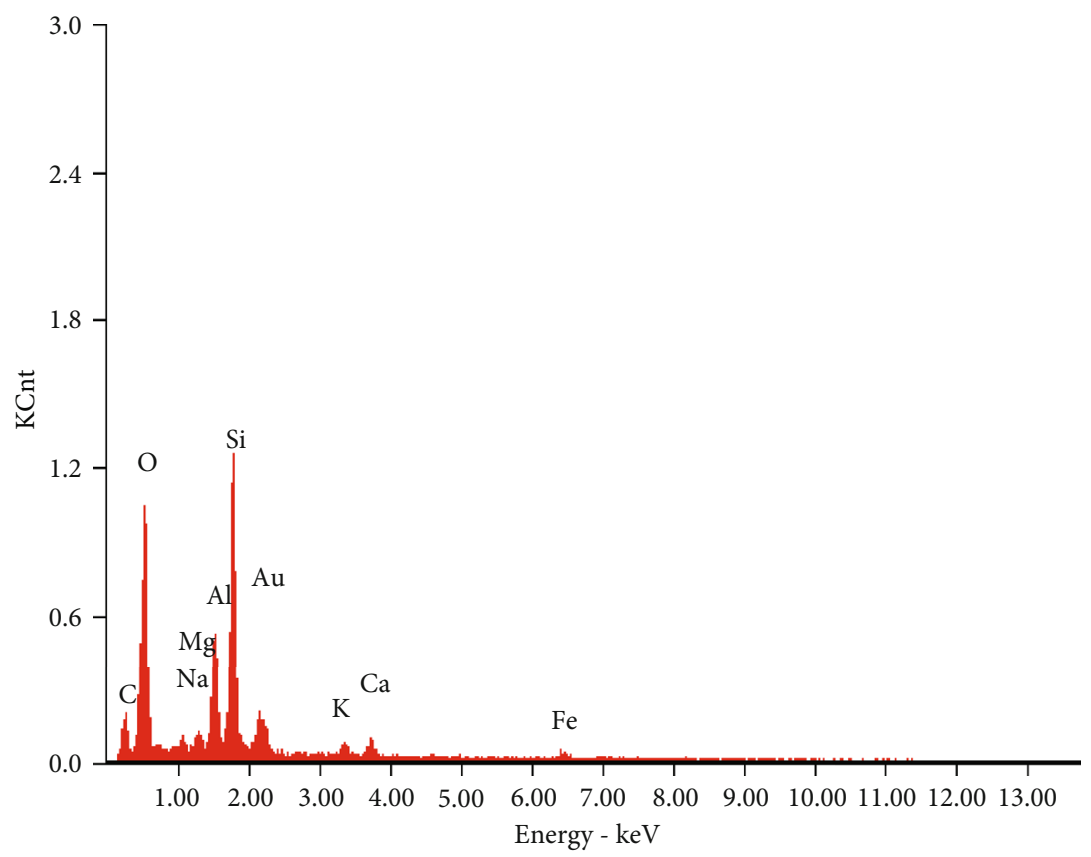

(d)

Figure 12: Continued. 


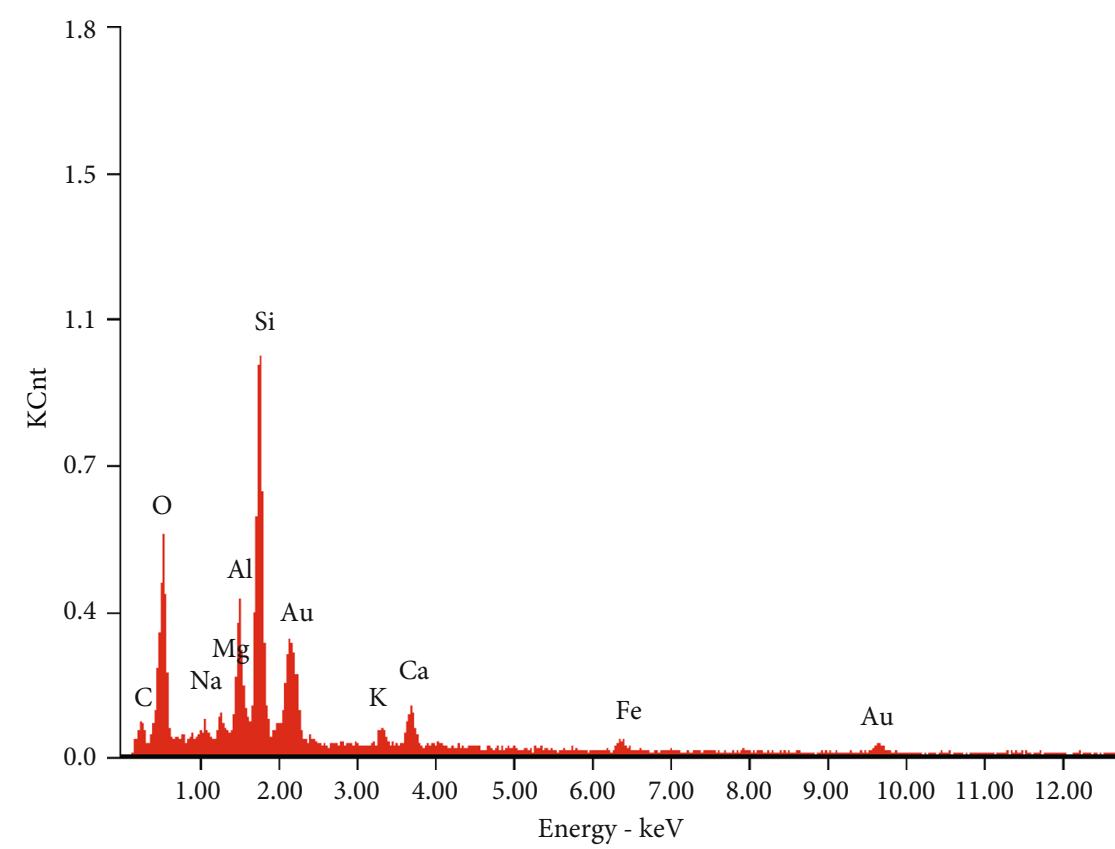

(e)

Figure 12: EDX spectra of (a) untreated soil, (b) soil with $0.75 \%$ PF, (c) soil with $1.5 \%$ PF, (d) soil with $2.25 \%$ PF, and (e) soil with $3 \%$ PF.

laboratory tests to determine the compaction, shear strength, consolidation, bearing resistance, and microstructure of soil specimens stabilised with $0 \%, 0.75 \%, 1.5 \%, 2.25 \%$, and $3 \%$ PF. The key findings from this study are as follows:

(i) As the PF content increased, the PI decreased. The decreased in PI improved the stability and workability of the soil

(ii) As the PF content of the clay soil increased, its MDD increased and its OMC decreased, indicating improved compaction

(iii) As the PF content of the clay soil increased, its angle of internal friction $(\Phi)$ increased and its cohesion coefficient $(c)$ decreased, indicating improved shear strength. The maximum angle of internal friction and minimum cohesion coefficient were obtained with a $3 \%$ PF content

(iv) As the PF content of the clay soil increased, its void ratio, consolidation coefficient, and hydraulic conductivity all decreased, indicating improved consolidation

(v) As the PF content of the clay soil increased, its CBR increased

(vi) Finally, distinct microstructural differences observed between the unstabilised and stabilised clay soils suggest that the addition of PF alters the soil microstructure by creating bonds between the soil and PF to improve its overall stability

The findings of this study demonstrate the potential for the use of PF as part of a soil stabilising technique. This is expected to contribute to the development of effective, codified methods to improve the safety and stability of such soils and thus the engineering structures built atop them.

\section{Data Availability}

The data used to support the findings of this study are available from the corresponding author upon request.

\section{Conflicts of Interest}

No conflict of interest was reported by the authors.

\section{Acknowledgments}

We gratefully acknowledge the financial support for this research from the Civil Engineering Department of Northeast Forestry University, Harbin, PR. China.

\section{References}

[1] A. Sezer, G. İnan, H. R. Yilmaz, and K. Ramyar, "Utilization of a very high lime fly ash for improvement of Izmir clay," Building and Environment, vol. 41, no. 2, pp. 150-155, 2006.

[2] M. Al-Mukhtar, S. Khattab, and J.-F. Alcover, "Microstructure and geotechnical properties of lime-treated expansive clayey soil," Engineering Geology, vol. 139-140, pp. 17-27, 2012.

[3] M. A. Lav and A. H. Lav, "Effects of stabilization on resilient characteristics of fly ash as pavement material," Construction and Building Materials, vol. 54, pp. 10-16, 2014.

[4] E. Garzón, M. Cano, B. C. O'Kelly, and P. J. Sánchez-Soto, "Phyllite clay-cement composites having improved engineering properties and material applications," Applied Clay Science, vol. 114, pp. 229-233, 2015. 
[5] Y. Yilmaz, "Compaction and strength characteristics of fly ash and fiber amended clayey soil," Engineering Geology, vol. 188, pp. 168-177, 2015.

[6] A. Al-Swaidani, I. Hammoud, and A. Meziab, "Effect of adding natural pozzolana on geotechnical properties of lime- stabilized clayey soil," Journal of Rock Mechanics and Geotechnical Engineering, vol. 8, no. 5, pp. 714-725, 2016.

[7] E. Garzón, M. Cano, B. C. O 'Kelly, and P. J. Sánchez-Soto, "Effect of lime on stabilization of phyllite clays," Applied Clay Science, vol. 123, pp. 329-334, 2016.

[8] S. T. Gilazghi, J. Huang, S. Rezaeimalek, and S. Bin-Shafique, "Stabilizing sulfate-rich high plasticity clay with moisture activated polymerization," Engineering Geology, vol. 211, pp. 171178, 2016.

[9] J. S. Yadav and S. K. Tiwari, "A study on the potential utilization of crumb rubber in cement treated soft clay," Journal of Building Engineering, vol. 9, pp. 177-191, 2017.

[10] H. Ali and M. Mohamed, "The effects of lime content and environmental temperature on the mechanical and hydraulic properties of extremely high plastic clays," Applied Clay Science, vol. 161, pp. 203-210, 2018.

[11] J. P. Temga, A. B. Madi, S. B. Djakba et al., "Lime - and sand stabilization of clayey materials from the Logone valley (Lake Chad basin) for their utilisation as building materials," Journal of Building Engineering, vol. 19, pp. 472-479, 2018.

[12] L. Wei, S. X. Chai, H. Y. Zhang, and Q. Shi, "Mechanical properties of soil reinforced with both lime and four kinds of fiber," Construction and Building Materials, vol. 172, pp. 300-308, 2018.

[13] S. Islam, N. M. R. Hoque, M. A. Haque, P. N. Mishra, M. M. H. Mamun, and S. Dey, "Strength development in fine-grained paddy field soil by lime addition," Journal of Building Engineering, vol. 26, article 100857, 2019.

[14] H. Güllü and A. Khudir, "Effect of freeze-thaw cycles on unconfined compressive strength of fine- grained soil treated with jute fiber, steel fiber and lime," Cold Regions Science and Technology, vol. 106-107, pp. 55-65, 2014.

[15] A. Boz and A. Sezer, "Influence of fiber type and content on freeze-thaw resistance of fiber reinforced lime stabilized clay," Cold Regions Science and Technology, vol. 151, pp. 359-366, 2018.

[16] M. Ding, F. Zhang, X. Ling, and B. Lin, "Effects of freeze-thaw cycles on mechanical properties of polypropylene fiber and cement stabilized clay," Cold Regions Science and Technology, vol. 154, pp. 155-165, 2018.

[17] E. Kravchenko, J. Liu, W. Niu, and S. Zhang, "Performance of clay soil reinforced with fibers subjected to freeze-thaw cycles," Cold Regions Science and Technology, vol. 153, pp. 18-24, 2018.

[18] Y. L. Xiong, G. B. Liu, R. Y. Zheng, and X. H. Bao, "Study on dynamic undrained mechanical behavior of saturated soft clay considering temperature effect," Soil Dynamics and Earthquake Engineering, vol. 115, pp. 673-684, 2018.

[19] Z. Sun and Q. Xu, "Microscopic, physical and mechanical analysis of polypropylene fiber reinforced concrete," Materials Science and Engineering: A, vol. 527, no. 1-2, pp. 198-204, 2009.

[20] S. N. Monteiro, V. Calado, R. J. S. Rodriguez, and F. M. Margem, "Thermogravimetric behavior of natural fibers reinforced polymer composites-an overview," Materials Science and Engineering: A, vol. 557, pp. 17-28, 2012.
[21] R. Noorzad and P. F. Amini, "Liquefaction resistance of Babolsar sand reinforced with randomly distributed fibers under cyclic loading," Soil Dynamics and Earthquake Engineering, vol. 66, pp. 281-292, 2014.

[22] A. A. S. Correia, P. J. Venda Oliveira, and D. G. Custódio, "Effect of polypropylene fibres on the compressive and tensile strength of a soft soil, artificially stabilised with binders," Geotextiles and Geomembranes, vol. 43, no. 2, pp. 97-106, 2015.

[23] B. R. Phanikumar and R. Singla, "Swell-consolidation characteristics of fibre-reinforced expansive soils," Soils and Foundations, vol. 56, no. 1, pp. 138-143, 2016.

[24] J. S. Yadav and S. K. Tiwari, "Behaviour of cement stabilized treated coir fibre-reinforced clay-pond ash mixtures," Journal of Building Engineering, vol. 8, pp. 131-140, 2016.

[25] S. Bordoloi, R. Hussain, A. Garg, S. Sreedeep, and W. H. Zhou, "Infiltration characteristics of natural fiber reinforced soil," Transportation Geotechnics, vol. 12, pp. 37-44, 2017.

[26] S. Orasutthikul, D. Unno, and H. Yokota, "Effectiveness of recycled nylon fiber from waste fishing net with respect to fiber reinforced mortar," Construction and Building Materials, vol. 146, pp. 594-602, 2017.

[27] A. A. Diab, S. S. Najjar, S. Sadek, H. Taha, H. Jaffal, and M. Alahmad, "Effect of compaction method on the undrained strength of fiber-reinforced clay," Soils and Foundations, vol. 58, no. 2, pp. 462-480, 2018.

[28] P. F. Amini and R. Noorzad, "Energy-based evaluation of liquefaction of fiber-reinforced sand using cyclic triaxial testing," Soil Dynamics and Earthquake Engineering, vol. 104, pp. 4553, 2018.

[29] K. Q. Tran, T. Satomi, and H. Takahashi, "Effect of waste cornsilk fiber reinforcement on mechanical properties of soft soils," Transportation Geotechnics, vol. 16, pp. 76-84, 2018.

[30] P. J. V. Oliveira, A. A. S. Correia, and J. C. A. Cajada, "Effect of the type of soil on the cyclic behaviour of chemically stabilised soils unreinforced and reinforced with polypropylene fibres," Soil Dynamics and Earthquake Engineering, vol. 115, pp. 336-343, 2018.

[31] M. Bekhiti, H. Trouzine, and M. Rabehi, "Influence of waste tire rubber fibers on swelling behavior, unconfined compressive strength and ductility of cement stabilized bentonite clay soil," Construction and Building Materials, vol. 208, pp. 304313, 2019.

[32] N. Esmaeilpour Shirvani, A. Taghavi Ghalesari, M. K. Tabari, and A. J. Choobbasti, "Improvement of the engineering behavior of sand-clay mixtures using kenaf fiber reinforcement," Transportation Geotechnics, vol. 19, pp. 1-8, 2019.

[33] K. Q. Tran, T. Satomi, and H. Takahashi, "Tensile behaviors of natural fiber and cement reinforced soil subjected to direct tensile test," Journal of Building Engineering, vol. 24, article 100748, 2019.

[34] A. Ateş, "Mechanical properties of sandy soils reinforced with cement and randomly distributed glass fibers (GRC)," Composites Part B: Engineering, vol. 96, pp. 295-304, 2016.

[35] A. Kumar and D. Gupta, "Behavior of cement-stabilized fiberreinforced pond ash, rice husk ash-soil mixtures," Geotextiles and Geomembranes, vol. 44, no. 3, pp. 466-474, 2016.

[36] P. Jamsawang, H. Poorahong, N. Yoobanpot, S. Songpiriyakij, and P. Jongpradist, "Improvement of soft clay with cement and bagasse ash waste," Construction and Building Materials, vol. 154, pp. 61-71, 2017. 
[37] A. A. B. Moghal, B. C. S. Chittoori, B. M. Basha, and M. A. alShamrani, "Target reliability approach to study the effect of fiber reinforcement on UCS behavior of lime treated semiarid soil," Journal of Materials in Civil Engineering, vol. 29, no. 6, article 04017014, 2017.

[38] A. J. Puppala and C. Musenda, "Effects of fiber reinforcement on strength and volume change in expansive soils," Transportation Research Record, vol. 1736, no. 1, pp. 134-140, 2000.

[39] J. S. Yadav and S. K. Tiwari, "Effect of waste rubber fibres on the geotechnical properties of clay stabilized with cement," Applied Clay Science, vol. 149, pp. 97-110, 2017.

[40] A. A. B. Moghal, B. C. S. Chittoori, and B. M. Basha, "Effect of fibre reinforcement on CBR behaviour of lime-blended expansive soils: reliability approach," Road Materials and Pavement Design, vol. 19, no. 3, pp. 690-709, 2018.

[41] N. M. Al-Akhras, M. F. Attom, K. M. Al-Akhras, and A. I. H. Malkawi, "Influence of fibers on swelling properties of clayey soil," Geosynthetics International, vol. 15, no. 4, pp. 304-309, 2008.

[42] A. A. B. Moghal, B. C. S. Chittoori, B. M. Basha, and A. M. AlMahbashi, "Effect of polypropylene fibre reinforcement on the consolidation, swell and shrinkage behaviour of lime-blended expansive soil," International Journal of Geotechnical Engineering, vol. 12, no. 5, pp. 462-471, 2017.

[43] F. S. Khan and S. Azam, "Determination of consolidation behaviour of clay slurries," International Journal of Mining Science and Technology, vol. 26, no. 2, pp. 277-283, 2016.

[44] H. Cui, Z. Jin, X. Bao, W. Tang, and B. Dong, "Effect of carbon fiber and nanosilica on shear properties of silty soil and the mechanisms," Construction and Building Materials, vol. 189, pp. 286-295, 2018.

[45] ASTM D 854-02: Standard test method for specific gravity of soil solids by water pycnometer, American Society for Testing and Materials, West Conshohocken, PA, 2006.

[46] ASTM D 422-63: Standard test method for particle-size analysis of soils, American Society for Testing and Materials, West Conshohocken, PA, 2006.

[47] ASTM D 4318-00: Standard test methods for liquid limit, plastic limit, and plasticity index of soils, American Society for Testing and Materials, West Conshohocken, PA, 2006.

[48] ASTM, D2487-00: Standard Practice for Classification of Soils for Engineering Purposes (Unified Soil Classification System), American Society for Testing and Materials, West Conshohocken, PA, 2006.

[49] ASTM D 698-00a: Standard test methods for laboratory compaction characteristics of soil using standard effort (12, $400 \mathrm{ft}$ $\left.l b f / \mathrm{ft}^{3}\left(600 \mathrm{kN}-\mathrm{m} / \mathrm{m}^{3}\right)\right)$, American Society for Testing and Materials, West Conshohocken, PA, 2006.

[50] ASTM D 2850-03a: Standard test method for unconsolidatedundrained triaxial compression test on cohesive soils, American Society for Testing and Materials, West Conshohocken, PA, 2006.

[51] C. Tang, B. Shi, W. Gao, F. Chen, and Y. Cai, "Strength and mechanical behavior of short polypropylene fiber reinforced and cement stabilized clayey soil," Geotextiles and Geomembranes, vol. 25, no. 3, pp. 194-202, 2007.

[52] J. S. Yadav, S. K. Tiwari, and P. Shekhwat, "Strength behaviour of clayey soil mixed with pond ash, cement and randomly distributed fibres," Transportation Infrastructure Geotechnology, vol. 5, no. 3, pp. 191-209, 2018.
[53] GB/T 50123-1999 Standard for Soil Test Method, Standardization Administration of China, Beijing, 1999.

[54] JTG E40-2007 Test Methods of Soils for Highway Engineering, Ministry of Transportation, Beijing, China, 2007.

[55] B. Mishra and M. K. Gupta, "Use of randomly oriented polyethylene terephthalate (PET) fiber in combination with fly ash in subgrade of flexible pavement," Construction and Building Materials, vol. 190, pp. 95-107, 2018.

[56] F. Changizi and A. Haddad, "Strength properties of soft clay treated with mixture of nano- $\mathrm{SiO}_{2}$ and recycled polyester fiber," Journal of Rock Mechanics and Geotechnical Engineering, vol. 7, no. 4, pp. 367-378, 2015.

[57] L. L. Zeng, Z. S. Hong, Y. Q. Cai, and J. Han, "Change of hydraulic conductivity during compression of undisturbed and remolded clays," Applied Clay Science, vol. 51, no. 1-2, pp. 86-93, 2011.

[58] K. S. Heineck, R. G. Lemos, J. A. A. Flores, and N. C. Consoli, "Influence of particle morphology on the hydraulic behavior of coal ash and sand," Geotechnical and Geological Engineering, vol. 28, no. 4, pp. 325-335, 2010.

[59] A. A. B. Moghal, B. M. Basha, B. Chittoori, and M. A. AlShamrani, Effect of fiber reinforcement on the hydraulic conductivity behavior of lime-treated expansive soil-reliabilitybased optimization perspective, vol. 263, ASCE Geotech Special Publication, 2016.

[60] P. V. Divya, B. V. S. Viswanadham, and J. P. Gourc, "Hydraulic conductivity behaviour of soil blended with geofiber inclusions," Geotextiles and Geomembranes, vol. 46, no. 2, pp. 121-130, 2018. 